\title{
Ecological and Biological Studies on the Citrus Flower Moth, Prays citri (Millière) (Lepidoptera: Hyponomeutidae). Abd El-Kareim, A. I. ${ }^{1}$; S. A. Moustafa ${ }^{2}$; Dina M. Fathy ${ }^{1}$ and T. M. Amara ${ }^{2}$ \\ ${ }^{1}$ Economic Entomology Dept., Fac. of Agric., Mansoura Univ., Egypt. \\ ${ }^{2}$ Plant Protection Research Institute, Agric. Res. Center, Giza, Egypt.
}

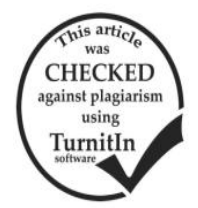

\section{ABSTRACT}

The present investigation indicated that the citrus flower moth, Prays citri (Millière) showed that differences in their response to host plant species. However, P. citri population greatly preferred lime over navel orange and mandarin. Lime flowers received the highest numbers of $P$. citri throughout the whole period of investigation, while no infestation occurred on mandarin. Navel orange flowers were of intermediate rank for $P$. citri population. The obtained results illustrated that both larval and pupal populations exhibited one peak of seasonal abundance during 2015 and 2016 seasons. Distribution of $P$. citri population within host plants, based on the analysis of variance, was affected by directions. However, $P$. citri population was significantly higher at the south direction than the other cardinal directions (north, west and east) and center of the canopies. The present study showed that $P$. citri population exhibited positive response to the increase of mean temperature, while, it showed negative response to both relative humidity and wind speed. No significant differences were observed between the duration periods of all developmental stages which reared on different host (lime, navel orange and mandarin) flowers. Analysis of life table of $P$. citri population indicated that mortality of larval stage is the Key-stage mortality, which can induce population changes comparing to other specific stage mortalities.

\section{INTRODUCTION}

In Egypt, citrus is the most important fruit as far as its acreage, production and exportation potentials (ElKassas, 1984). Citrus trees are mostly infested with many pests which affect their productivity such as flower moths and fruit flies. The citrus flower moth (CFM), Prays citri Millière (Lepidoptera: Hyponomeutidae), is regarded as a key pest of citrus in parts of the Mediterranean region (Toth et al., 2009), including Portugal (Silva et al., 2006), Sicily (Conti and Fisicaro, 2015) and Egypt (AboSheaesha, 1994). Sweet lime, Citrus aurantifolia (Christm.) is the most susceptible species to the pest, followed by lemon, sweet orange, mandarin and grapefruit. On clementine, $P$. citri only caused damage at the time of flowering, and this was seldom of economic importance. Also the citrus flower moth attacks flowers of Ligustrum lucidum Ait, (Sinacori and Mineo, 1997).

CFM causes economic damage to different Citrus species, particularly to lemon flowers. The larva feeds both internally and externally on flowers, flower buds and small fruits (Carimi et al., 2000 and EFSA, 2008). P.citri caused a loss of $30-40 \%$ of citron crop, during the year (Talhouk, 1969, and Perez-Ibanez et al. 1973), in case of heavy infestation. The cumulative percentages reached 72.8-99.8. According to Mineo et al. (1980) infestation of flowers and fruits with P.citri reached over 50\%, and flower infestation reached $100 \%$ in May and June.

For the success of management control program, it is essential to know several information concerning the biology and ecology of the pest (Abd El-Kareim, 1992). Temperature, relative humidity and wind speed are important environmental factors that affect the success of an insect to live in a given environment. The study of these parameters is interesting for insect of economic importance to obtain a useful orientation for good forecasting and prediction system of insect population (Dahi, 2003).

Therefore, the present studies aim to elucidate the following principal objectives:

- Host plant $-P$. citri interactions.

- Seasonal population trends of P. citri in lime orchard.

- Spatial distribution of $P$. citri in different directions of lime trees:
- Response of $P$. citri population to the changes in temperature, relative humidity and wind speed.

- Influence of host plant species on the biology of P. citri.

- Determine the key-stage mortality which may cause changes in the insect population.

\section{MATERIALS AND METHODS}

Estimation the seasonal abundance of Prays citri

1. Seasonal abundance of $\boldsymbol{P}$. citri in response to host plant species

To evaluate the seasonal abundance of $P$. citri in response to each host plant (lime, navel orange and mandarin), four trees of each host plant homogenous in size and age were selected and marked for the present study. Samples were weekly collected at the beginning of the first flushes flowering period. Each sample consisted of 100 flowers / host plant (25 flowers / tree) which were picked up at random from the different cardinal directions (north, south, east and west) and the center of the tree (five flowers / direction). Sampling was started from mid. of February to the end of April during the first season (2015) and from the last week of February to the end of April during the second season (2016). Each sample of each direction was put in a plastic cup and transported to the laboratory for investigation. Numbers of larvae and pupae were counted and recorded.

\section{- Seasonal abundance of $\boldsymbol{P}$. citri in response to weather} factors

To study the role of main weather factors (i.e. temperature, relative humidity and wind speed) on the seasonal activity of $P$. citri, daily records of mean temperature along with relative humidity and wind speed were obtained from the Agro meteorological Station at ElTahrir district, El-Beheira governorate during 2015 and 2016 seasons. The daily records of each weather factor were grouped into weekly means according to the sampling dates. Correlation and regression analysis were done between the weekly averages of each weather factor and the seasonal abundance of the insect population.

Influence of host species on some biological aspects of $P$. citri

Insect source

The citrus flower moths were obtained in the larval stage from flowers of lime trees located in El-Tahrir 
district, Beheira governorate. P. citri larvae were confined in Petri-dishes with a perforated cover and provided with adequate amount of lime, navel orange or mandarin flowers. Inspection was conducted until pupation and kept until adult emergence. The sex of the emerged adults was determined on the basis of morphological differences between the terminal segments of the abdomen (Carimi et $a l, 2000$ ), and pairs of a female and a male were kept separately in tubes for the experiments.

To estimate the influence of host plant species (lime, navel orange and mandarin) on the duration of each developmental stage of $P$. citri, females emerged from each host plant were released into a cylinder glass jars (each jar measured $10 \mathrm{~cm}$ in diameter and $25 \mathrm{~cm}$ in height) and kept until deposit eggs. These jars were provided with $10 \%$ sucrose solution for moths' feeding. Fine branches of each host plant contained a lot of flowers were introduced into the jar for oviposition.

Fifty newly deposited eggs were investigated daily until hatching. After egg hatching, twenty newly hatched larvae were separately confined in Petri-dishes with a perforated cover and provided with two fresh flowers (renewal daily) of lime, navel orange or mandarin for larval feeding until pupation. Inspection was conducted till adult emergence. This experiment was replicated three times. The durations of all developmental stages were estimated on the different citrus species infested with $P$. citri under laboratory conditions $\left(27.0 \pm 1.8^{\circ} \mathrm{C}\right.$ and $74.0 \pm 4.0 \%$ R.H.).

Determine the key-stage mortality of $\boldsymbol{P}$. citri

The percentage of mortality during each stage were estimated to study the age stage mortality of $P$. citri, numbers of emerged adults (males and females) were released in the previously mentioned glass jar to have a laboratory culture. An initial population of $P$. citri was started as 50 newly deposited eggs on fine branches of lime contained a lot of flowers that were introduced into the jar for oviposition under laboratory conditions $\left(27.0 \pm 1.8^{\circ} \mathrm{C}\right.$ and $74.0 \pm 4.0 \%$ R.H.). A test was replicated three times for each generation (50 newly deposited eggs/ replicate).

To estimate the stage-specific survival (Ix) life tables were constructed with the following columns:

Ix : The number of survivals at the beginning of age class $\mathrm{x}$.

$\mathrm{dx}$ : The number of deaths during the age interval $\mathrm{x}$.

k- value: Killing power acting on each developmental stage, which is the difference between the logarithm of the initial and final populations.

To assess the relative contribution of various stagespecific mortality to the total generation mortality, the following $\mathrm{k}$ - values were calculated:

$\mathrm{k}_{1}, \mathrm{k}_{2}$ and $\mathrm{k}_{3}$ : mortality of egg, larval and pupal stages, respectively.

$\mathrm{K}$ : Total generation mortality.

Key factor analysis: To determine the key-stage specific mortality the largest coefficient for the relation "k" on "K" (Podolar and Rogers, 1975).

\section{RESULTS}

Host plant preference to citrus flower moth, $\boldsymbol{P}$. citri Data presented in Figure (1) show the general mean of population density of $P$. citri as affected by host plant species throughout two seasons (2015 and 2016) on lime, navel orange and mandarin trees.

As shown in Figure (1) lime flowers harboured the highest average number of $P$. citri throughout the whole period of investigation, while mandarin flowers did not invaded by $P$. citri, where the observed average numbers of the pest individuals was nil. Navel orange flowers were of intermediate rank for $P$. citri population. The general mean of $P$. citri population on lime flowers was significantly higher (5.07 \pm 4.16 individuals/ sample) than that of navel orange $(0.28 \pm 0.28)$ and mandarin $(0.0)$ during 2015 season. In the second season (2016), the same trend was observed, where flowers of lime, navel orange and mandarin were invaded by $5.05 \pm 3.54,0.16 \pm 0.21$ and 0.0 individuals/ sample, respectively.

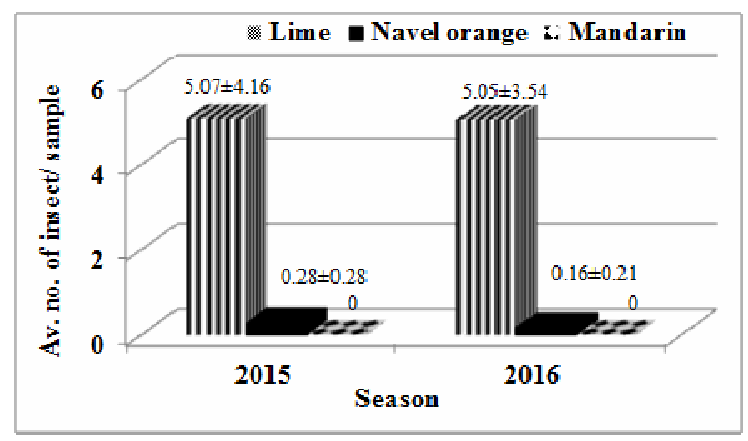

Figure 1. Average number of Prays citri individuals/ sample on lime, navel orange and mandarin during 2015 (LS.D. = 2.7, $\mathrm{P=5 \%}$ ) and 2016 (LS.D. $=\mathbf{2 . 0 6}, \mathrm{P}=5 \%$ ) seasons.

\section{Seasonal abundance of $\boldsymbol{P}$. citri population in lime orchard}

Flower samples were used to illustrate the seasonal abundance of the citrus flower moth, $P$. citri inhibiting lime orchard.

\section{- Larval stage population}

The average number of $P$. citri larvae / 5 flowers collected through weekly samples from lime flowers during 2015 and 2016 seasons are graphically illustrated in Figure (2). The first appearance of $P$. citri larvae was recorded during the ultimate week of February with few individuals, then larval population gradually increased to show the highest occurrence on April 10th, represented by 2.05 individuals / 5 flowers showing the highest peak. After that larval population gradually decreased toward the end of flowering period. In the second season (2016), larval population (Figure, 2) had similar trend. It was recorded from the first week of March to the last week of April. According to the abundance of $P$. citri individuals on lime trees, a peak was occurred on the 1st of April with an average of 1.9 individuals $/ 5$ flowers.

\section{b) Pupal stage population}

As shown in Figure (2), the pupal population of $P$. citri started to appear on lime flowers with very low number ( 0.05 and 0.1 individuals / 5 flowers) on the $6^{\text {th }}$ and $11^{\text {th }}$ of March during the first and second seasons, respectively. Then, the mean number of pupae gradually increased to reach the highest abundance on the $17^{\text {th }}$ and $29^{\text {th }}$ of April, represented by 0.5 and 0.45 individuals / 5 flowers during 2015 and 2016, respectively. 


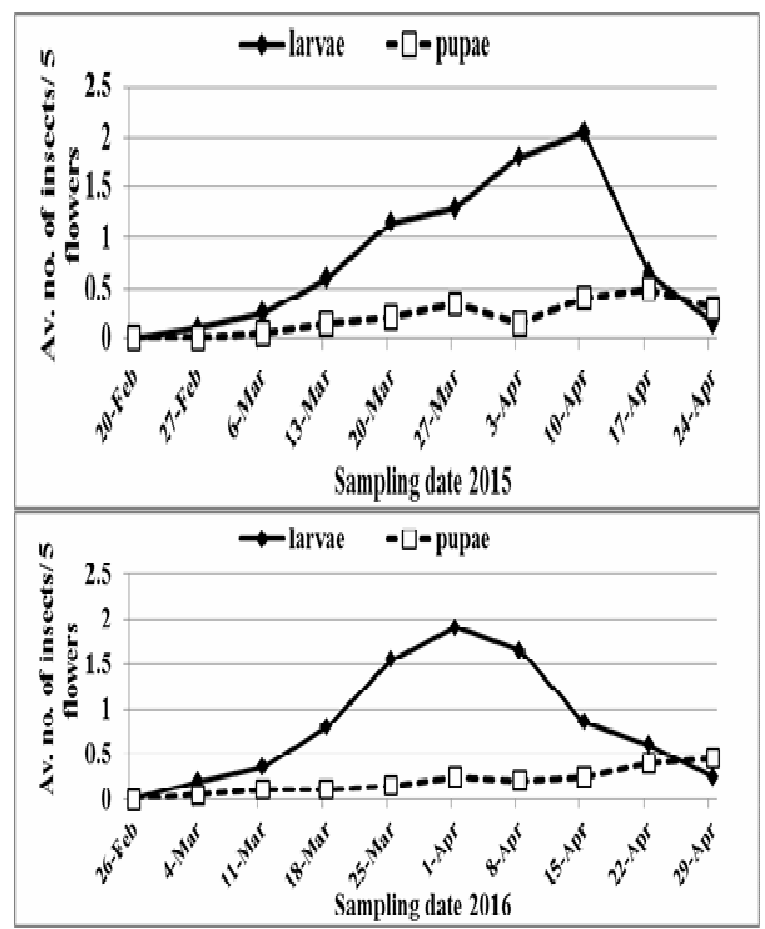

Figure 2. Seasonal abundance of Prays citri larval and pupal stages (number of larvae or pupae / 5 flowers) on lime flowers at ElTahrir district, Beheira governorate during 2015 and 2016 flowering seasons.
Seasonal activity of $P$. citri in response to certain weather factors

Data in Tables (1 and 2) show the seasonal activity of $P$. citri in the lime orchard in response to mean of air temperature, relative humidity and wind speed at El-Tahrir district, Beheira governorate during spring flowering seasons of 2015 and 2016. In the first season (2015), $P$. citri population recorded the highest peak of 2.45 insects/ 5 flowers on the $10^{\text {th }}$ of April at $18.4^{\circ} \mathrm{C}, 68.4 \%$ R.H. and 15.1 $\mathrm{km} / \mathrm{hr}$ of wind speed. But, during the second season (2016), the highest peak ( 2.15 individuals/ 5 flowers) took place on the first of April at $16.4^{\circ} \mathrm{C}, 70.7 \%$ R.H. and 12.6 $\mathrm{km} / \mathrm{hr}$ of wind speed (Table, 1). As shown in Table (2), the population of citrus flower moth exhibited significantly positive response to temperature $(\mathrm{r}=0.66)$ during 2015 flowering season, while the correlation was insignificantly positive $(r=0.15)$ during the second season. On the other hand, the population of $P$. citri showed insignificantly negative correlation with the prevailing relative humidity during the two seasons of investigation. Finally, the correlation between population of CFM and wind speed was insignificantly positive $(\mathrm{r}=0.03)$ during 2015 flowering season, but it was negatively insignificant $(r=$ 0.26 ) during the second season of 2016.

To evaluate the common effect of the three tested environmental factors (mean temperature, relative humidity and wind speed) on $P$. citri population, multiregression analysis was done. The combined effect of temperature, relative humidity and wind speed on the pest population were $49 \%$ in the first season, and was low (represented by $25.5 \%$ ) in the second season (Table, 2).

Table 1. Population density of Prays citri (Av. no. of larvae and pupae/5 flowers) in lime orchard in response to the changes of mean temperature, relative humidity and wind speed at El-Tahrir district, ElBeheira Governorate during 2015 and 2016 flowering season.

\begin{tabular}{|c|c|c|c|c|c|c|c|c|c|}
\hline \multirow[b]{2}{*}{$\begin{array}{l}\text { Sampling } \\
\text { date }\end{array}$} & \multicolumn{4}{|c|}{2015} & \multicolumn{5}{|c|}{2016} \\
\hline & $\begin{array}{c}\text { Av. no. } \\
\text { of insect }\end{array}$ & $\begin{array}{l}\text { Mean } \\
\text { Temp. }\end{array}$ & $\begin{array}{c}\text { Mean } \\
\text { R.H.\% }\end{array}$ & $\underset{\operatorname{speed}(\mathbf{k m} / \mathbf{h r})}{\text { Wind }}$ & $\begin{array}{c}\text { Sampling } \\
\text { date }\end{array}$ & $\begin{array}{c}\text { Av. no. of } \\
\text { insects }\end{array}$ & $\begin{array}{l}\text { Mean } \\
\text { Temp. }\end{array}$ & $\begin{array}{c}\text { Mean } \\
\text { R.H.\% }\end{array}$ & $\begin{array}{r}\text { Wind } \\
\text { speed } \\
(\mathrm{km} / \mathrm{hr})\end{array}$ \\
\hline February20 & 0 & 11.0 & 76.6 & 15.1 & February 26 & 0 & 17.0 & 69.4 & 17.9 \\
\hline 27 & 0.1 & 14.3 & 76.9 & 16.9 & March 4 & 0.25 & 16.7 & 75.3 & 11.6 \\
\hline March 6 & 0.3 & 14.4 & 73.3 & 9.9 & 11 & 0.45 & 16.0 & 72.7 & 13.7 \\
\hline 13 & 0.75 & 15.9 & 78.3 & 12.6 & 18 & 0.9 & 17.6 & 67.0 & 18.0 \\
\hline 20 & 1.35 & 14.9 & 68.7 & 11.0 & 25 & 1.7 & 18.3 & 61.9 & 14.7 \\
\hline 27 & 1.65 & 16.7 & 69.9 & 14.9 & April & 2.15 & 16.4 & 70.7 & 12.6 \\
\hline April 3 & 1.95 & 17.9 & 69.7 & 15.4 & 8 & 1.85 & 20.3 & 67.9 & 12.9 \\
\hline 10 & 2.45 & 18.4 & 68.4 & 15.1 & 15 & 1.1 & 19.3 & 74.1 & 16.0 \\
\hline 17 & 1.15 & 14.7 & 74.3 & 14.1 & 22 & 1 & 20.6 & 69.3 & 8.9 \\
\hline 24 & 0.45 & 18.6 & 58.7 & 16.9 & 29 & 0.65 & 22.3 & 64.6 & 15.9 \\
\hline
\end{tabular}

Table 2. Correlation and regression coefficients between $P$. citri population and weather factors (temperature, relative humidity and wind speed) in lime orchard during 2015 and 2016 seasons.

\begin{tabular}{|c|c|c|c|c|c|c|c|c|}
\hline \multirow[t]{2}{*}{ Year } & \multirow{2}{*}{$\begin{array}{c}\text { Weather factor } \\
\text { Mean }\end{array}$} & \multicolumn{4}{|c|}{ Correlation and simple regression } & \multicolumn{3}{|c|}{ Multi regression analysis } \\
\hline & & $\mathbf{r}$ & b & $\mathbf{P}$ & $R^{2} \%$ & b & $\mathbf{P}$ & E.V.\% \\
\hline \multirow{3}{*}{2015} & Temp. & $0.66^{*}$ & 0.24 & 0.039 & 43.2 & 0.31 & 0.077 & \multirow{3}{*}{49} \\
\hline & R.H. & $-0.32^{\text {n.s. }}$ & -0.05 & 0.375 & 9.9 & 0.04 & 0.556 & \\
\hline & Wind speed & $0.03^{\text {n.s. }}$ & 0.88 & 0.940 & 0.8 & -0.05 & 0.651 & \\
\hline \multirow{3}{*}{2016} & Temp. & $0.15^{\text {n.s. }}$ & 0.05 & 0.674 & 2.3 & -0.04 & 0.797 & \multirow{3}{*}{25.5} \\
\hline & R.H. & $-0.33^{\text {n.s. }}$ & -0.06 & 0.346 & 11.1 & -0.08 & 0.288 & \\
\hline & Wind speed & $-0.26^{\text {n.s. }}$ & -0.07 & 0.460 & 6.9 & -0.10 & 0.324 & \\
\hline
\end{tabular}

Spatial distribution of $P$. citri in different directions of lime trees

Data illustrated in Figure (3) show the spatial distribution of $P$. citri in different directions (east, west, north, south and center) of lime trees during the two successive flowering seasons of 2015 and 2016. Distribution of $P$. citri population within the canopy of host plants, based on the analysis of variance, differently varied according to the cardinal directions and middle of the lime trees. Significant difference of the population density of $P$. citri was observed among cardinal directions (north, west, south and east) and center, on lime trees. However, P. citri population was significantly higher at the south direction than the other cardinal directions (north, west and east) and center of the canopies (Figure, 3). As shown in Figure (3), $P$. citri population was the highest in south direction compared to the other directions during the first and second seasons with means of $1.27 \pm 0.27$ and $1.50 \pm 0.43$ 
individuals/5 flowers, respectively. On contrary, the lowest population of $P$. citri was recorded in north directions $(0.77 \pm 0.41)$ during the first season; while, during the second season, the lowest population was recorded in west direction ( $0.75 \pm 0.33$ individuals/5 flowers).

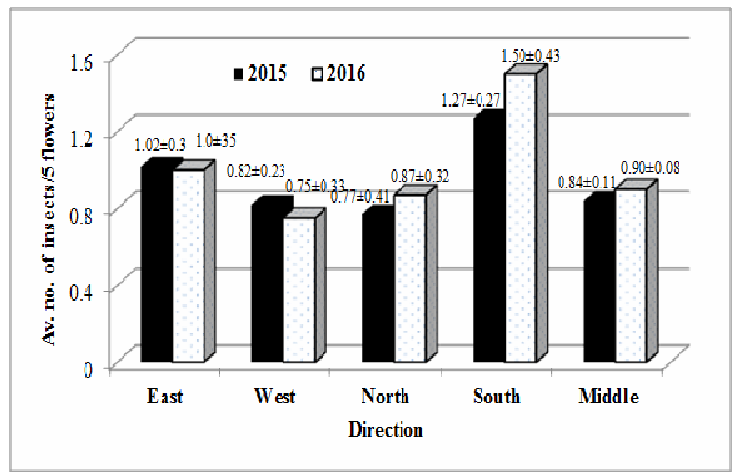

Figure 3. Population density of Prays citri in cardinal direction and center of lime trees at El-Tahrir district, El-Beheira governorate all over 2015 and 2016 flowering seasons (L.S.D. $=0.42$ and 0.49 during 2015, and 2016).

Influence of different citrus species on some biological aspects of $\boldsymbol{P}$. citri

The effect of different citrus flowers (lime, navel orange and mandarin) on the development of $P$. citri immature stages were studied under laboratory conditions $\left(27.0 \pm 1.8^{\circ} \mathrm{C}\right.$ and $74.0 \pm 4.0 \%$ R.H.). Data in Table (3) indicate that the duration of each developmental stage un affected by host plant species. The incubation period of $P$. citri eggs on all tested species was approximately the same recording $4.22 \pm 0.67,4.33 \pm 0.71$ and $4.56 \pm 0.73$ days on lime, navel orange and mandarin flowers, respectively. The shortest duration of larval stage was $8.0 \pm 0.89$ days for larvae reared on navel orange flowers followed by $8.13 \pm 0.64$ and $8.33 \pm 0.82$ days on lime and mandarin flowers. The pupal period insignificantly recorded $4.20 \pm 0.45,4.33 \pm 0.52$ and $4.60 \pm 0.55$ days on navel orange, lime and mandarin flowers, respectively. Also, the total immature stages of $P$. citri insignificantly showed $16.68 \pm 2.23,16.53 \pm 2.16$ and $17.49 \pm 2.17$ days on lime, navel orange and mandarin, respectively. The longest duration of $P$. citri immature stages was recorded when larvae were reared on mandarin flowers (Table, 3 )

Table 3. Duration of the immature stages (in days) of the citrus flower moth, $P$. citri reared on lime, navel orange and mandarin flowers under laboratory conditions.

\begin{tabular}{lcccc}
\hline Stage & \multicolumn{1}{c}{ Lime } & Navel orange & Mandarin & L.S.D \\
\hline Egg & $4.22 \pm 0.67$ & $4.33 \pm 0.71$ & $4.56 \pm 0.73$ & $0.68^{\text {ns }}$ \\
Larva & $8.13 \pm 0.64$ & $8.0 \pm 0.89$ & $8.33 \pm 0.82$ & $0.94^{\text {ns }}$ \\
Pupa & $4.33 \pm 0.52$ & $4.20 \pm 0.45$ & $4.60 \pm 0.55$ & $0.69^{\text {ns }}$ \\
Total immature & $16.68 \pm 2.23$ & $16.53 \pm 2.16$ & $17.49 \pm 2.17$ & $1.75^{\text {ns }}$ \\
stages & & &
\end{tabular}

\section{Age-specific mortality of $\boldsymbol{P}$. citri}

Mortality among (k-value) larval stage was much higher than in other stages (Table, 4). The killing power ( $\mathrm{k}$ value) among they was $0.33,0.39$ and 0.28 for the $1^{\text {st }}, 2^{\text {nd }}$, and $3^{\text {rd }}$ generations, respectively. On the contrary, the pupal mortality was relatively low in the $1^{\text {st }}, 2^{\text {nd }}$, and $3^{\text {rd }}$ generations recording k-value of $0.058,0.073$ and 0.048 , respectively.

As shown in (Table, 4) the total mortality from eggs to adult stage was considerably varied from a generation to another. Analysis of factors contributing to age stagespecific mortality indicated that the determining key-stage specific mortality on the basis of regression coefficient of $\mathrm{k}$-values was $\mathrm{k}_{2}$ (Figure, 4). Regression analysis illustrated that the regression of $\mathrm{k}_{2}$ values on $\mathrm{K}$ showed the highest slope $(b=0.59)$ for larvae, while the slope values of $k_{1}$ and $\mathrm{k}_{3}$ on $\mathrm{K}$ were $(0.27$ and 0.14$)$. So, $\mathrm{k}_{2}$ appeared to be the key-stage mortality which could induce population changes of $P$. citri.
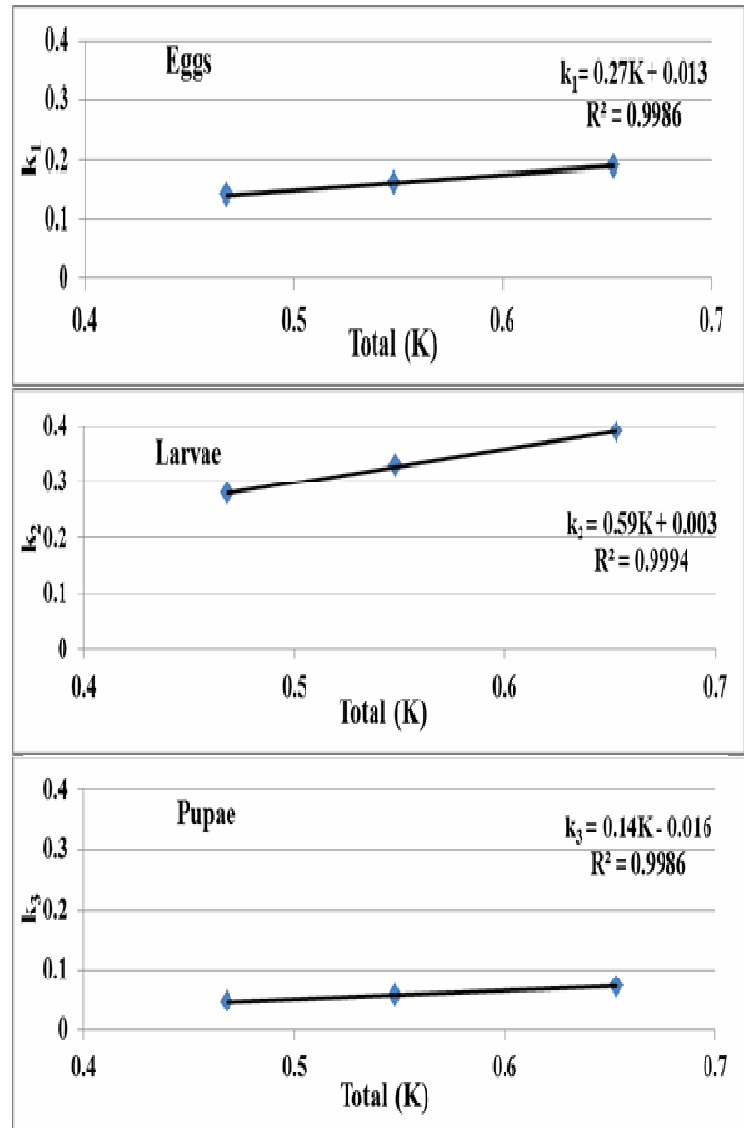

Figure 4. The k-values for the different citrus flower moth mortalities plotted against the total generation mortalities.

Table 4. Life table of the citrus flower moth, $P$. citri reared on lime flowers over three generations (G) under laboratory conditions.

\begin{tabular}{|c|c|c|c|c|c|c|c|c|c|}
\hline \multirow{2}{*}{ Stage } & \multicolumn{3}{|c|}{$\mathbf{I x}$} & \multicolumn{3}{|c|}{$\mathbf{d x}$} & \multicolumn{3}{|c|}{ k-value } \\
\hline & $\mathbf{G}_{1}$ & $\mathbf{G}_{2}$ & $\mathbf{G}_{3}$ & $\mathbf{G}_{1}$ & $\mathbf{G}_{2}$ & $\mathbf{G}_{3}$ & $\mathbf{G}_{1}$ & $\mathbf{G}_{2}$ & $\mathbf{G}_{3}$ \\
\hline Eggs & 50 & 50 & 50 & 16 & 18 & 14 & 0.16 & 0.19 & 0.14 \\
\hline Larvae & 34 & 32 & 36 & 18 & 19 & 17 & 0.33 & 0.39 & 0.28 \\
\hline Pupae & 16 & 13 & 19 & 2 & 2 & 2 & 0.058 & 0.073 & 0.048 \\
\hline Newly emerged adults & 14 & 11 & 17 & - & - & - & - & - & - \\
\hline Total $(\mathrm{K})$ & - & - & - & - & - & - & 0.548 & 0.653 & 0.468 \\
\hline
\end{tabular}




\section{DISCUSSION}

\section{Seasonal activity of $\boldsymbol{P}$. citri in lime orchards}

The present results revealed that $P$. citri populations exhibited the highest abundance on lime in comparison with navel orange and mandarin trees. Also, Ibrahim and Shahateh (1984) reported that sweet lime (Citrus aurantifolia) was the species most susceptible to $P$. citri, followed by lemon, sweet orange, mandarin and grapefruit in order of decreasing susceptibility. According to Surin (1992) and Abo-Sheaesha (1994), lime and navel orange flowers are the most favorable hosts for $P$. citri larvae, while, mandarin is the least favorable host. El-Sayed et al. (1994) demonstrated that the volatile odors from different citrus flowers may activate (e.g., limonene and citronellol) or inhibit (e.g., nerol, terpineol, beta -caryophyllene, methyl lantheranlate and geraniol) females to lay eggs.

$P$. citri population showed a single peak of activity on lemon flowers at the end of main flowering period (the first half of April) after a gradual increase from the late of February. These results are in agreement with those obtained by Buchelos et al. (1963) in Greece and Mineo et al. (1980 and 1991) in addition to Sinacori and Mineo (1997) in Sicily who found that $P$. citri activity showed an increase at the end of main flowering period of lemon (at the late of May in Greece and at May-June in Sicily). By using sex pheromone traps in citrus orchards, Garrido et al. (1984) stated that $P$. citri were found throughout the year in eastern Spain exhibiting two peaks; in May-July and October-November. They added that the largest population was occurred when the trees carried the maximum number of flower buds. While, in Lebanon, Talhouk (1969) reported that $P$. citri was most sever in November and February. In Portugal, $P$. citri exhibited its highest peaks of activity during July and October (Mendonca et al., 1997).

From the obtained results, it can be concluded that the highest activity of $P$. citri was recorded when mean temperature was 18.4 and $16.4^{\circ} \mathrm{C}$ (during the first and second seasons, respectively). These results are supported by Burgio et al. (1974) who found that the maximum number of laid eggs was obtained at $20^{\circ} \mathrm{C}$. According to statistical analysis of the present study, mean temperature and relative humidity exhibited relatively low effects on $P$. citri population. While, Mineo et al. (1980) reported that climatic and cultural factors had considerable effects on $P$. citri activity in Sicily. The variations between the present results and others may be attributed to the variations of climatic and/or cultural factors; however, Mineo et al. (1980) added that the activity of $P$. citri varied so much according to time of year and locality. With respect to wind speed, there was insignificantly positive and negative correlation between $P$. citri and the changes of mean wind speed during the first and second years of study. According to Jonason et al. (2014) flight activity of micro moths is markedly affected by wind speed with no flight occurring above at wind speeds greater than $10 \mathrm{~km} / \mathrm{hr}$. Wind speeds above $8 \mathrm{~km} / \mathrm{hr}$ reduce the moth flight activity.

Significant difference of the population density of $P$. citri was observed among cardinal directions (north, west, south and east) and center, of lime trees. However, $P$. citri population was significantly higher at the south direction than the other cardinal directions (north, west and east) and center of the canopies. The causes of aggregation in these species might be due to their inherent active aggregative behavioral response such as in a situation where the presence of one individual attracts the others, and also due to some heterogeneity of the environment such as microclimate and preferred part of the plant (Southwood 1978 and Wratten \& Fry 1980).

\section{Biological aspects of $\boldsymbol{P}$. citri}

The present results indicate that incubation period of $P$. citri eggs were approximately similar on all tested host plants. These results are confirmed with those obtained by Ibrahim and Shahateh (1984), Surin (1992) and Abo-Sheaesha (1994) who reported that incubation period of this pest ranged between 2-9 days. The duration of all developmental stages slightly varied according to the host plant, where lime and navel orange flowers are the most favorable hosts for development of $P$. citri larvae. While, mandarin is the least favorable host. The duration of immature stages lasted 16.90 days; these results are in agreement with those obtained by Abo-Sheaesha (1994) who found that life cycle of $P$. citri lasted a period from 12 to 51 days according to the time of year. While, Carimi et al. (2000) mentioned that the life cycle of this pest on callus lasted about 21 days.

According to the present study, the durations of larval and pupal stages ranged between ( 8.0 and 8.33 days) and (4.2 and 4.6 days), respectively. Also, Ibrahim \& Shahateh (1984) and Abo-Sheaesha (1994) mentioned that the durations of larval and pupal stages ranged between 625 and 3-12 days, respectively; while, Surin (1992) mentioned that these stages lasted between $22-30$ and 5-7 days, respectively under laboratory conditions.

Analysis of life table of $P$. citri population indicated that mortality of larval stage is the Key-stage mortality, which can induce population changes comparing to the other specific stage mortalities. While, Abo-Sheaesha (1994) found that larval mortality percentages ranged between 28.4 and $46.9 \%$. The variations between the present results and the others may be attributed to the variations of experimental conditions and/or host plant species/varieties.

\section{REFERENCES}

Abd EL-Kareim, A.I. (1992). Life table studies on the purple scale insect, Lepidosaphes beckii New (Homoptera: Diaspididae). Com In. Sci. Dev. Res., 40: 195 - 206.

Abo-Sheaesha, M.A. (1994). Studies on Prays citri Mill. (Lepidoptera, Hyponomeutidae) and it is control. PhD Thesis, Fac. of Agric., Al- Azhar University.

Buchelos, T.C.; S.T. Soweref and T.A. Tsokas (1963). Observations on the biology of Prays citri Mill. in Greece. Rep. Minsist. Agric., Phytopath. Sat. P. 26.

Burgio, G.; G. Maniglia and G. Mineo (1974). Influence of temperature on the oviposition and life-span of Prays citri Mill. Bollettino dell'Istituto di Entomologia Agraria e dell' Osservatorio di Fitopatologia di Palermo, 9:129-141. 
Carimi, F.; V. Caleca; G. Mineo; F. de Pasquale and F.G. Crescimanno (2000). Rearing of Prays citri on callus derived from lemon stigma and style culture. Entomologia Experimentalis et Applicata, 95: 251257.

Conti, F. and R. Fisicaro (2015). Integrated strategies to monitor and control citrus flower moth, Prays citri (Lepidoptera: Yponomeutidae) on nursery trees of the Mediterranean area. Acta Horticulturae, (1065):1165-1171.

Dahi, H.F. (2003). Predicting the annual generations of spiny bollworm, Earias insulana (Biosd) (Lepidoptera : Arctiidae). Ph. D. Thesis, Fac. Agric., Cairo Univ.

EFSA (European Food Safety Authority) (2008). Pest risk assessment made by France on Prays citri considered by France as harmful in French overseas departments of French Guiana, Guadeloupe and Martinique1. The EFSA J. 680: 2-22

El-Kassas, S.E. (1984). Effect of iron nutrition on the growth, yield, fruit quality, and leaf composition of seeded Balady lime trees grown in sandy calcareous soils. Journal of Plant Nutrition, 7(1-5): 301-311.

El-Sayed, E.M.; M.S. Talaat; S. El-Desouki and M.A. Sheashaa (1994). Bioelectrical activity of citrus flower moth. Prays citri and host plant selection for oviposition. Egyptian Journal of Biomedical Engineering, 10: 31-48.

Garrido, A.; T. del. Busto and J. Tarancón (1984). Assessment of adults of Prays citri Mill. (Lep., Hyponomeutidae) with a synthetic pheromone and the relation to damage. Anales del Instituto Nacional de Investigaciones Agrárias, Agrícola, 25: 147-154.

Ibrahim, S.S. and W.A. Shahateh (1984). Biological studies on the citrus flower moth Prays citri Miller in Egypt. Arab Journal of Plant Protection, 2 (1): 4-9.

Jonason, D.; M. Franzen and T. Ranius (2014). Surveying moths using light traps: Effects of weather and time of year. Published online (2014) Mar 17. doi: 10.1371/ journal. pone.0092453R.

Mendonca, T.R.; F.M. Martins, and M.P. Lavadinho (1997). Flight pattern of the citrus moth Prays citri (Milliere) (Lepidoptera, Yponomeutidae) in a lemon orchard in Mafra and development of attack intensity. Boletin de Sanidad Vegetal, Plagas, 23(3):479-483.
Mineo, G.; E. Mirabello; T. del. Busto and G. Viggiani (1980). Catches of adults of Prays citri Mill. (Lep., Plutellidae) with pheromone traps and progress of infestations in lemon groves in eastern Sicily. Bollettino del Laboratorio di Entomologia Agraria 'Filippo Silvestri', Portici, 37: 177-197.

Mineo, G.; M.A. Sciacchitano and A. Sinacori (1991). Observations on the phenology of the preimaginal stages of Prays citri Mill. (Lep., Hyponomeutidae). Redia, 74 (1): 225-232.

Perez-Ibanez, T.; J. Alberti-Maurico; G. Martinez-Canales Murcia and P. Vinaches Gomis (1973). Development of larvae of Prays citri Mill. in the months of April, May, June and July. Boletin Informativo de Plagas, (108):17-27.

Podolar, H. and D. Rogers (1975). A new method for the identification of key factors from life table data. J. Anim.Ecol., 44: 85-114.

Silva, E.B. da; R. Gaspar; L. Dias; R. Antunes; I. Lourenco; J. Clemente and J.C. Franco (2006). Developing a mating disruption tactic for pest management of citrus flower moth. Bulletin OILB/SROP, 29(3): 127137.

Sinacori, A. and N. Mineo (1997). Two new host plants of Prays citri and Contarinia sp. Informatore Fitopatologico, 47(7/8): 13-15.

Surin, B. (1992). Study on live history of rind borers (Prays citri) and their infestation at Trat Province. Food and Agriculture Organization of the United Nations.

Southwood, T.R.E. (1978). Ecological methods. Great Britain. Univ. Printing House, Cambridge, pp. 524.

Talhouk, A.M.S. (1969). Insects and mites injurious to crops in Middle Eastern countries. Mongrathien Zur Angew. Entomologie, Zeitschrift Fur Angew. Entomolo. Nr. 21:239 pp. Verlag paul parey. Hamburg and Berlin.

Toth, M.; R. Tabilio and F. di Franco (2009). Developing semiochemical tools for monitoring, mass trapping and integrated control of potential pests of citrus and Mediterranean fruit crops. Protezione delle Colture, (3): 34-39.

Wratten, S.D. and G.L.A. Fry (1980). Field and laboratory exercises in ecology. Edward Arnold, London, 227 pp.

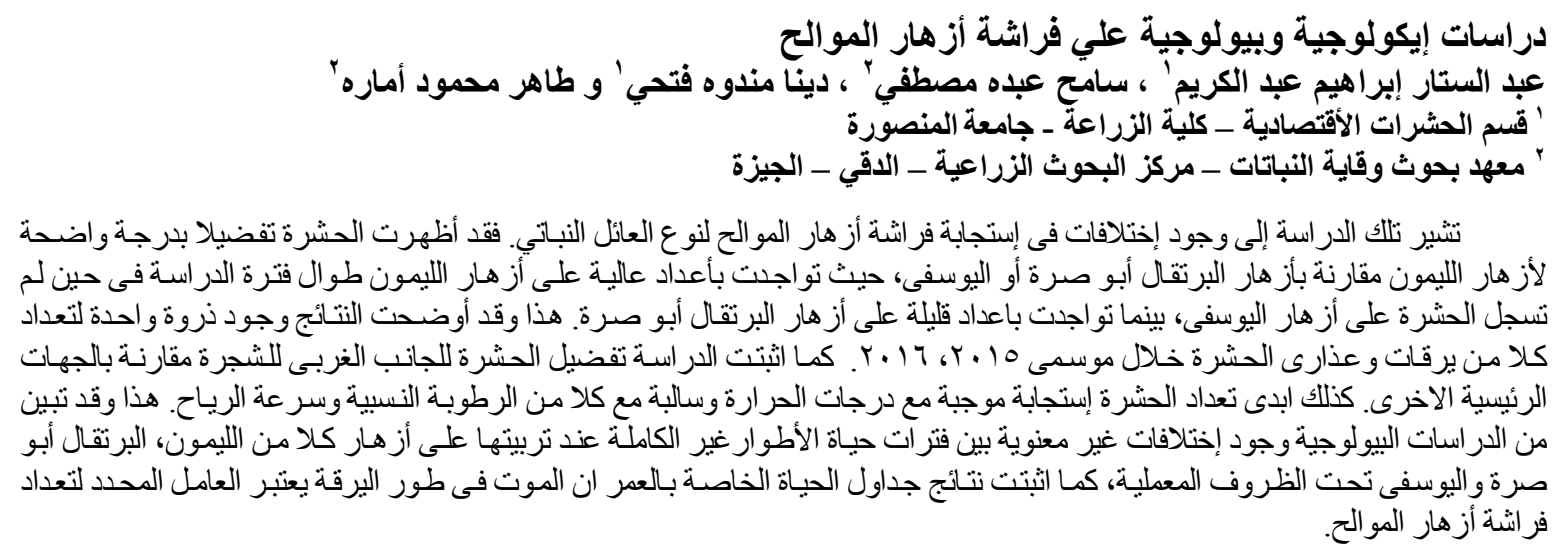

